\title{
Investigating the role of leadership in safety outcomes within oil and gas organisations
}

\author{
John Ojuola ${ }^{1}$ Sherif Mostafa ${ }^{2}$ and Sherif Mohamed $^{3}$ \\ ${ }^{1,2,3}$ Griffith School of Engineering and Built Environment \\ Corresponding author’s E-mail: john.ojuola@griffithuni.edu.au
}

\begin{abstract}
For many countries, the oil and gas industry is regarded as one of the most lucrative and key sources of energy. Tasks in this sector can be classified under five main stages - exploration, oil extraction, refining, transporting and marketing of oil and its byproducts. Such tasks pose substantial risks to the environment, personnel and community at large. When accidents occur in the industry, the likelihood of human fatality is very high. Organisations where safety is highly critical (i.e. high exposure to risk and likelihood of an accident) poses particular challenges for leaders. Thus, such organisations call for specific leadership/leadership behaviours, which may differ from those most effective in less safety-critical organisations. Therefore, this paper examines some key accidents in the oil and gas industry that had huge influence on the development of safety legislations. The paper is centred on the literature review and the selected accidents; based on the following themes - leadership, safety culture, safety outcomes, and safety climate. Discussions on the study carried out was presented, followed by a framework for safety leadership. Finally, this paper concludes that safety-critical organisations require leadership that influences followers to behave safely, acts as a role model and exhibits profound concern for safety.
\end{abstract}

Abbreviations: MHF: Major Hazard Facilities; BSEE: Bureau of Safety and Environmental Enforcement; SEMS: Safety and Environment Management System; SPE: Society of Petroleum Engineers; ALARP: As Low As Reasonable Practical; SCOs: Safety-Critical Organisations

Keywords: Safety; Leadership; Safety outcomes; Safety culture; Safety climate; Safety leadership framework; Key accidents in oil and gas

\section{Introduction}

For many countries, the oil and gas industry is regarded as one of the most lucrative and key sources of energy; with an international consumption of about 179 quadrillion British thermal unit (Btu) in 2010 and a projected figure of 197 quadrillion Btu by 2020 (U.S. Energy Information Administration, 2014). This has prompted the need for an increase in the production of oil, gas and other byproducts. Tasks in this sector can be classified under four main stages - exploration, oil extraction, refining, transporting and marketing of oil and its byproducts (Schneider et al., 2011); and entails several multifaceted, expensive, and risky activities that necessitate well-grounded evaluations before investments. The stages listed above pose substantial risks to the environment, personnel and community health and safety, and safety of the facilities themselves. Hence, accidents that occurred in this sector over decades were due to the nature and quantities of chemicals and products used and the complexity of processes, along with poor management of manpower, material and machineries. 
Therefore, this paper examines selected accidents in the oil and gas industry, and various themes centred around the role of leadership in safety outcomes. Finally, research findings and discussions on the study carried out will be presented, followed by the introduction of a framework for safety leadership.

\section{Research methodology}

The aim of this paper is to investigate the role of leadership in safety out-comes within the oil and gas industry. To achieve this, qualitative data on safety leadership within major accidents in the oil and gas industry was used. This study was centred around five (5) key accidents that had the most influence on safety legislations between 1979 and 2010. The cases selected focussed on the role leadership played in the outcome of safety. This research is designed into three stages as follows:

- Stage 1: Review of the related literature on the five studied cases in oil and gas,

- Stage 2: Research findings and analysis of safety measures and leadership, and

- Stage 3: Development of a framework for safety leadership.

\section{Safety in the oil and gas industry}

Accidents in the workplace can occur from a number of causes including leadership failures, poor safety culture, lack of safety monitoring, inadequate management supervision, faulty equipment, defiance to change, conflicting priorities, and inapposite safety behaviour, to mention a few (McBride \& Collinson, 2011). These causes are amplified in the oil and gas industry due to adverse environments, highly combustible fossil fuels, restricted spaces, heights, and heavy equipment that employees are exposed to or use recurrently (Pinheiro et al., 2011).

Workers in oil refineries are exposed to flammable and explosive conditions on a daily basis. Accidents (which involve injuries and death) are not just restricted to the rig sites. Other operatives, such as drivers are exposed to greater risk of vehicular accidents than workers of most other industries (Saleh et al., 2014). Stride et al. (2013) noted that corporate leaders usually push for increase in production over safety concerns. Ironically, this type of attitude is also widespread in the oil and gas industry, as delay in production can lead to remarkable loss of revenue (Pinheiro et al., 2011).

\section{Key accidents in the oil and gas industry}

Case study is one of the most frequently used qualitative research methodologies. Yin (2003) defined case as a contemporary phenomenon within its real-life context, especially when the boundaries between a phenomenon and context are not clear and the researcher has little control over the phenomenon and context. Given this definition, from Yin's point of view, case study is an empirical inquiry that investigates the case or cases conforming to the above-mentioned definition by addressing the 'how' or 'why' questions concerning the phenomenon of interest.

Taking a cue from Yin's definition above, some key accidents in the oil and gas industry that had huge influence on the development of safety legislations are summarised in Table 1: 
Table 1: Main Characteristics of the Selected Accidents

\begin{tabular}{lclll}
\hline Project & Year & Location & Description & Result \\
\hline Bohai 2 Oil Rig & 1979 & $\begin{array}{l}\text { Gulf of } \\
\text { Bohai, } \\
\text { China }\end{array}$ & $\begin{array}{l}\text { Punctured hole in the deck and } \\
\text { resulted in extensive flooding. Sixth } \\
\text { most fatal offshore oil rig disaster. }\end{array}$ & 72 fatality (out of 76). \\
\hline $\begin{array}{l}\text { Piper Alpha Drilling } \\
\text { Platform }\end{array}$ & 1988 & $\begin{array}{l}\text { North Sea, } \\
\text { Scotland }\end{array}$ & $\begin{array}{l}\text { Natural gas condensate leak } \\
\text { resulted in explosions and fires. } \\
\text { Worst disaster in the history of the } \\
\text { oil \& gas industry. }\end{array}$ & 167 lives lost. \\
\hline $\begin{array}{l}\text { Esso Longford Gas } \\
\text { Plant }\end{array}$ & 1998 & $\begin{array}{l}\text { Victoria, } \\
\text { Australia }\end{array}$ & $\begin{array}{l}\text { Release of hydrocarbon vapours } \\
\text { and liquids led to gas plant } \\
\text { explosion. }\end{array}$ & $\begin{array}{l}\text { 2 fatality; 8 injuries; gas } \\
\text { supply interrupted for } \\
\text { 3weeks. }\end{array}$ \\
\hline $\begin{array}{l}\text { Texas City Oil } \\
\text { Refinery }\end{array}$ & 2005 & $\begin{array}{l}\text { Texas, } \\
\text { USA }\end{array}$ & $\begin{array}{l}\text { Explosions caused by hydrocarbon } \\
\text { ignition. }\end{array}$ & $\begin{array}{l}\text { 15 fatality; 180 injuries; } \\
\text { billions of dollars in victim } \\
\text { compensation. }\end{array}$ \\
\hline $\begin{array}{l}\text { Deepwater Horizon } \\
\text { Drilling Platform }\end{array}$ & 2010 & $\begin{array}{l}\text { Gulf of } \\
\text { Mexico, } \\
\text { USA }\end{array}$ & $\begin{array}{l}\text { Gas released from the well to the } \\
\text { platform caused explosion and fire. } \\
\text { Largest offshore spill in the history } \\
\text { of the oil industry. }\end{array}$ & $\begin{array}{l}\text { 11 fatality recorded; } 4.9 \\
\text { million barrels of oil released } \\
\text { into the Gulf (long-term } \\
\text { impact of oil-spill on the } \\
\text { ecosystem still unclear). }\end{array}$ \\
\hline
\end{tabular}

A full description of the selected accidents and their outcomes are outlined below:

- Bohai 2 oil rig, China, November 1979

The sixth most fatal offshore oil rig disaster is the Bohai 2 oil rig disaster which took place in November 1979. Out of the 76 people on board, 72 fatality was recorded (Duddu, 2014). Fierce winds broke the ventilator pump of the platform while the rig was being towed, causing a puncture hole in the deck and resulting in extensive flooding. This eventually led to loss of stability and capsizing of the jack-up. It was believed that the crew members lacked proper training on emergency evacuation procedures and the use of lifesaving equipment, and the accompanying tow boat could not rescue them. This subsequently led to the high fatality rate recorded for the Bohai 2 oil rig disaster.

Post-disaster inquiries revealed that standard tow procedures were not adhered to and there was failure in correctly stowing the deck equipment prior to towing. The remaining wreckage was eventually taken down with explosives in April 1981 (Duddu, 2014).

- The Piper Alpha drilling platform, Scotland, July 1988

The year 2018 marked the 30th anniversary of the Piper Alpha disaster in the North Sea, which is referred to as the worst disaster in the history of the oil and gas industry; in terms of loss of life. On the 6th of July 1988, a natural gas condensate leak resulted in explosions and fires that engulfed the Piper Alpha platform and claimed the lives of 167 people. The Piper Alpha tragedy and the subsequent investigations led by Lord Cullen practically reshaped the oil and gas industry. After the accident, the UK government, as led by the Scottish Judge Lord Cullen, initiated a judicial public inquiry into the Piper Alpha disaster. The inquiry lasted for two years and exposed several problems in the safety management 
system and deficiencies in the design of the platform. The exhaustive inquiry report proposed about 106 recommendations intended to avert the recurrence of such a dis-aster in the oil and gas industry (Cullen, 1990).

The Piper Alpha tragedy and the subsequent Cullen enquiry resulted in a change in the UK safety legislation. In 1992, the UK government introduced the offshore regulations (Safety Case). This was later updated in 2005 and then 2015. The Safety Case regime was soon adopted by other countries in the North Sea; the Netherlands, Denmark and Norway. The Safety Case concept was also adopted by some countries and oil companies in other parts of the world (Duddu, 2014).

- Esso Longford gas plant, Australia, September 1998

When the Esso Longford gas plant exploded 25 September 1998, supply to the state of Victoria in Australia was interrupted for about three weeks, as this was the main supplier of natural gas to the state. Investigations into the accident revealed that a shell and tube heat exchanger ruptured, thereby releasing hydrocarbon vapours and liquids. This was followed by explosions and fire, resulting in two fatalities and eight injuries (Elliot, 2001). Subsequently, two years after the Longford accident, in June 2000, the State of Victoria enacted the Occupational Health and Safety Regulations for Major Hazard Facilities (MHF) (Cooke \& Sheers, 2003).

- Texas City oil refinery, USA, March 2005

On March 23, 2005 an explosion rocked the BP Texas City refinery, killing 15 people and injuring 180 after the blowdown drum of the isomerisation unit overflowed (loss of containment of hydrocarbons), and a heat source ignited the ensuing vapours resulting in an explosion and subsequent pool fire (Saleh et al., 2014). The company incurred direct and indirect financial losses on the order of billions of dollars for victims' compensation as well as significant property damage and loss of production.

- Deepwater Horizon drilling platform, Macondo, USA, April 2010

Deepwater Horizon was a semi-submersible drilling platform operating in the Gulf of Mexico. Gas released from the well to the platform caused explosion and fire. The platform was destroyed and sank; 11 workers lost their life. The accident caused the largest offshore spill in the history of the oil industry with an about 4.9 million barrels of oil released into the Gulf of Mexico. The oil spill was widespread and covered an area between 6,500 and $176,100 \mathrm{~km} 2$ and the long-term impact on the ecosystem is still unclear (Pat-EI et al., 2014).

A year after the Macondo accident, the US government established the Bureau of Safety and Environmental Enforcement (BSEE). This federal agency was responsible for improving safety and ensuring environmental protection of oil and gas operations. All Operators are required to implement a Safety and Environment Management System (SEMS). In addition to developments in the management and training of offshore operations and drilling (with emphasis on deep water), the Macondo accident led to a new 
European Directive, which is a further development of the Safety Case regulations Directive 2013/30/EU (Pat-EI et al., 2014).

\section{Research findings and discussions}

The research findings and discussions are centred on the literature review and the selected accidents; and based on the following themes - leadership, safety culture, safety outcomes and safety climate.

\section{Leadership}

The Esso Longford Gas Plant report uncovered several issues - inadequate workers' training, leadership failure and inefficient facilities design. As accidents happen for various reasons, leaders need to understand how to improve safety practices in their organisations. Various studies have demonstrated that particular leadership behaviours have positive effects on safety (Clarke, 2013; Dahl \& Olsen, 2013). Hence, researchers and practitioners need to discover and understand the precursors to a safe work environment. And test particular leadership behaviours that emerge as having the greatest effect on these precursors, thus improving safety outcomes generally.

Oil and gas companies, academia and professional societies are actively investigating various aspects of human factors and process safety. As an example, the Society of Petroleum Engineers (SPE) published a technical report on process safety and human factors (Committee, 2014); leadership and culture came top on the list of factors identified. Also, Dalzell (2011) noted that 'Safety is a line responsibility. This is established both in law and in the culture of all responsible organisations. When it comes to occupational safety, most people in a managerial position should be competent and able to take on this responsibility' (p. 14).

Amanchukwu et al. (2015), emphasised that there is an increasing acceptance that good leadership, requires experience, awareness, dedication, perseverance and the ability to negotiate and work with others to achieve goals. Bass and Bass (2009) added that good leadership is achieved through a continuous process of training and practice. Jenkins (2013) stated that good leadership entails strong character and altruistic dedication to an organisation. Trustworthiness is highlighted as the key to positions of leadership, whatever the group or organisation (Ivancevich et al., 2007). Northouse (2018) described leadership as a process in which a person influences a group of persons to achieve a common goal.

\section{Safety culture}

Safety culture is an important concept for hazardous industries. It was introduced by the International Nuclear Safety Advisory Group in 1986 following the Chernobyl accident, and later became a staple of safety studies in academia and within a host of industries. The scope and meaning of the concept have evolved since it was first introduced, and although many definitions for it exist, it is generally agreed that safety culture of an organisation is the product of individual and group values, attitudes, perceptions, and patterns of behaviours that determine the commitment to and the proficiency of an organisation's to health and safety issues (Saleh et al., 2014).

In response to the Texas City refinery incident, three different investigation panels were convened and generally agreed that the accident resulted from a combination of factors, including design and operational flaws, technical and organisational factors, and more broadly a weak safety culture. The safety culture at the Texas City refinery was significantly weak, and this was manifest in a 
variety of ways, from poor safety practices, to inadequate procedures, and a repeated pattern of safety violations.

Poor safety practices, from inadequate communication between personnel to routine violations of operational procedures, were prevalent throughout the raffinate unit. According to the CSB report, formal procedure regarding communication between shifts was deficient and what little formal policy existed was not enforced (e.g. turnover procedures and records in logbooks).

\section{Safety outcomes}

The safety literature has demonstrated a clear positive link between leadership and safety outcomes (Kelloway et al., 2006). Some authors claim that active safety behaviour is also a critical area that should be empirically studied (Clarke, 2013). Positive links have thus been established between various forms of safety leadership, and a range of individual and group performance and safety outcome variables, such as workforce compliance and participation and safety climate (MartínezCórcoles et al., 2013).

Gaining an understanding of the precursors that influence employees' safety performance can prove vital for reducing the incidence of job-related injuries. Neal et al. (2000) highlighted two dimensions of safety performance: safety compliance defined as adhering to safety procedures and carrying out work in a safe manner and safety participation, defined as helping co-workers, promoting the safety programme in the workplace, demonstrating initiative and put-ting effort into improving safety in the workplace. Specifically, safety compliance consists of behaviours that are viewed as part of employees' formal job description, while safety participation includes behaviours, which are discretionary and extend beyond employees' formal work role (Neal et al., 2000).

\section{Safety climate}

Martínez-Córcoles and Stephanou (2017) defined safety climate as the employees' shared perceptions about their work environment in terms of safety. For the Piper Alpha platform accident, the centre of Cullen's (1990) report was in connection to the insufficiency of safety legislations. This led to the introduction in of the Offshore Installation Regulations (Safety Case) in 1992. This regulation demands the personnel in-charge show that the specific hazards and subsequent risks associated with the new facilities have been recognised, and appropriate measures have been taken to minimise these risks have been reduced to operatives on the facility to the ALARP (As Low As Reasonable Practical) level.

Several people assume that safety is the absence of accidents (or as an acceptable level of risk). Hollnagel et al. (2013) defined safety as a state whereas few things as possible go wrong (SafetyI). By this definition, safety is seen as a condition where the number of adverse outcomes (accidents/incidents/near misses) is as low as possible. This is achieved by ensuring that things do not go wrong, either by removing the causes of malfunctions and hazards, or by reducing their effects. However, since work situations are increasingly intractable, another definition of safety could be 'ensuring that everything goes right' (Safety-II) (Hollnagel et al. 2013). That is, a state where the number of successful outcomes is as high as possible. And this can be achieved by ensuring that things go right, rather than by averting them from going wrong.

Hollnagel et al. (2013) concluded by emphasising that both ways of thinking (Safety-I and Safety- 
II) represent two complementary views of safety rather than two incompatible or conflicting approaches. The specific balance of both approaches depends on a number of variables -type of work/project, experience of workforce, organisational climate, management, etc.

Following the catastrophic Piper Alpha disaster, safety in the oil and gas industry became a significant subject amongst various organisations - government and private. Many enacted regulations in the bid to improve the safety of processes and equipment. For instance, the European Union amended the Seveso I Directive twice in 1987 and 1988; so as to incorporate facilities that store dangerous substances (European Commission, 2015).

It is obvious that safety culture was a major challenge in the five accidents. Noticeably in the Texas City Oil Refinery project, there was weak safety culture, poor safety practices and inadequate communications. Similarly, leadership was not efficient in the accidents studied. In Deepwater Horizon Project, there was inadequate management and training of offshore operations and drilling. From the findings, shared perception about the environment with regards to safety (safety climate) was evidently absent in all the cases.

\section{Framework for safety leadership}

Often, accidents in any industry can amount to losses in tens of thousands of dollars, however, loss of profits is light as compared to the human lives. When accidents occur in the oil and gas industry, the likelihood of human fatality is very high (Eckle \& Burgherr, 2013). Thus, the need for leadership to take the improvement safety performance very seriously. Leaders need to understand the influences, social values, learning behaviours, and the various types of safety leadership behaviours crucial to improve safety performance (Cohen et al., 2011).

Safety in any organisation should be the leader's top priority (Ojuola et al., 2018). On the average, about one million people around the world experience accidents in the workplace; and on a daily basis, over 5,500 workers die from work-related accidents ( $\mathrm{Li}$ et al., 2013). Therefore, top-level leaders should understand that efficient safety leadership is essential for managing a safety-critical environment. Dunlap (2011) found that 'safety management must rise to be a core issue that leadership sees as an import-ant area for which they are directly responsible' (p. 45).

In recent years, interest in safety leadership has increased as researchers have consistently found that leadership is an important antecedent of employees' safety perceptions, attitudes and behaviours that drive safety outcomes (Conchie \& Donald, 2009; Kelloway et al., 2006). Safety leadership generally refers to a set of leadership behaviours that influence subordinates' behaviours to attain particular safety goals. Specifically, safety leadership can affect subordinates' behaviours on handling safety issues in both direct and indirect ways. The indirect ways could be the establishment of norms relating to safety practices and procedures, thus cultivating a particular safety culture. The direct ways could relate to their reinforcement of employees' safe behaviours through monitoring and control. As a result, these leadership behaviours directly and indirectly influence subordinates' expectations and motivations, thus influencing subordinates' safe or unsafe behaviours (Flin \& Yule, 2004). Lu and Yang (2010) identified three aspects of safety leadership: safety motivation, safety policy, and safety concern. 
This research study developed a framework which is based on the literature review, and findings from the cases studied. The framework comprises of five main components: leadership, safety culture, safety outcomes, safety climate and safety leadership as shown in Figure 1.

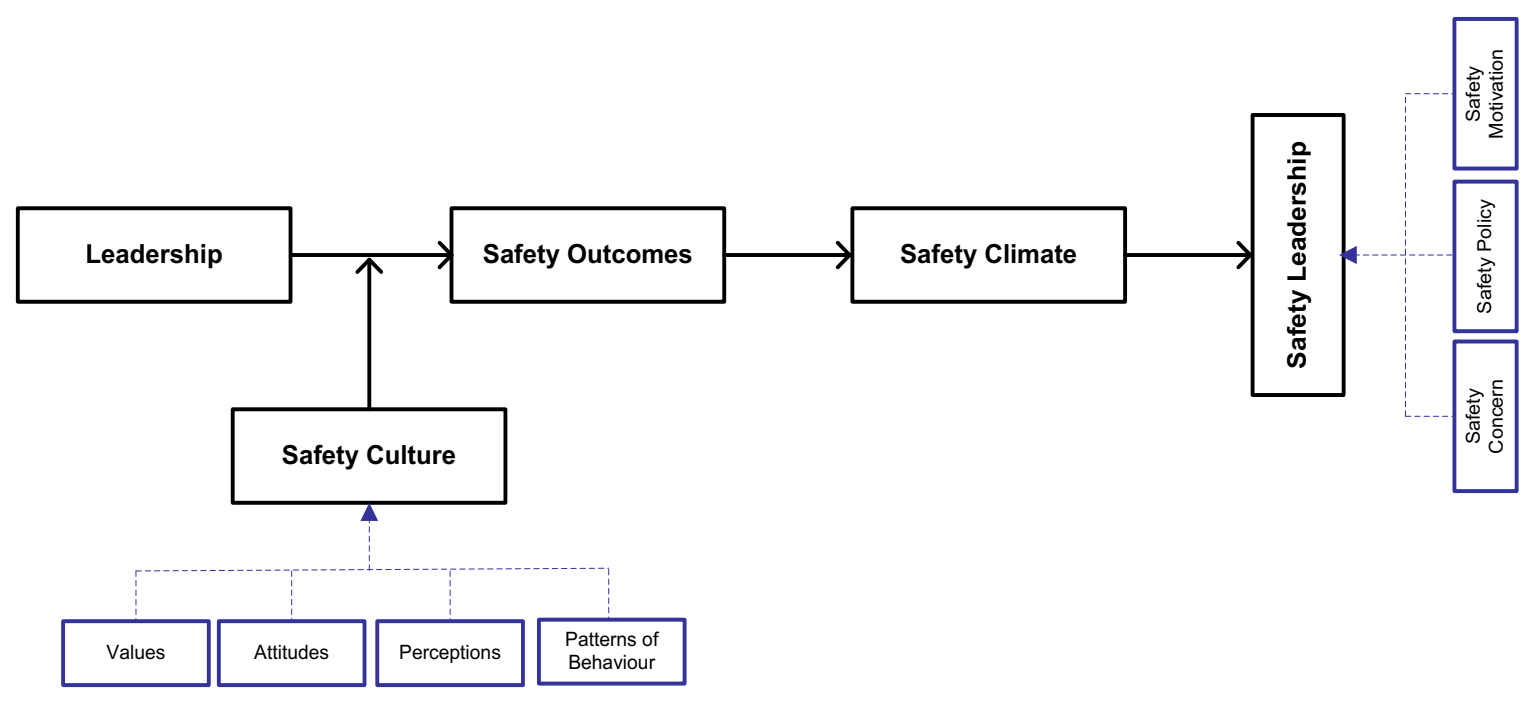

Figure 1: Safety Leadership Framework

Conchie (2013) noted that safety motivation and safety concern are dimensions of transformational leadership, while Clarke (2013) emphasised that safety policy is more aligned to transactional leadership. Safety motivation is known to occur when a leader influences follower to behave safely. Whereas, safety concern takes place when a leader acts as a role model, exhibiting profound concern for safety; and safety policy occurs when a leader creates clear rules, goals, and responsibilities.

\section{Conclusion}

Organisations where safety is highly critical (i.e. high exposure to risk and likelihood of an accident) poses particular challenges for leaders. Thus, such organisations call for specific leadership/leadership behaviours, which may differ from those most effective in less safety-critical organisations (SCOs). Despite the need for specific leadership for SCOs like we have in the oil and gas industry, predominant leadership theories have mainly been built on the bureaucratic patterns. Most leadership studies have been developed from research in social sciences on human relationships rather than focus-sing on studies of organisational top-bottom structures. The inability to move beyond formal leaders and control inherent in traditional bureaucratic mindsets limits the applicability of mainstream leadership theories for SCOs.

To address this challenge, a framework for safety leadership not based in bureaucracy is proposed. This framework focused on leadership that influences followers to behave safely, acts as a role model and exhibits pro-found concern for safety. Future research can adopt this framework as the foundation for further empirical studies. This study could investigate and map the relationships between the identified themes. 


\section{Disclosure statement}

No potential conflict of interest was reported by the author(s).

\section{Notes on contributors}

John Ojuola is a PhD Candidate at the School of Engineering and Built Environment, Griffith University. His research interest includes safety leadership.

Dr Sherif Mostafa is a Lecturer in Construction and Engineering Project Management at Griffith University. His research expertise includes BIM integration within prefabricated buildings and digital engineering.

Sherif Mohamed is a Professor and Head of School of Engineering and Built Environment at Griffith University. His principal research interest is construction workplace health and safety. He is actively engaged in scholarly research work and has authored and co-authored more than 200 refereed journal and conference publications.

\section{ORCID}

John Ojuola - http://orcid.org/0000-0001-6348-9040

Sherif Mostafa - http://orcid.org/0000-0002-5708-3770

Sherif Mohamed - http://orcid.org/0000-0002-8967-6212

\section{References}

Amanchukwu, R. N., Stanley, G. J., \& Ololube, N. P. (2015). A review of leadership theories, principles and styles and their relevance to educational management. Management, 5(1), 6-14.

Bass, B.M. \& Bass, R. (2009). The Bass handbook of leadership: Theory, research, and managerial applications. Simon and Schuster.

Clarke, S. (2013). Safety leadership: A meta-analytic review of transformational and transactional leadership styles as antecedents of safety behaviours. Journal of Occupational and Organisational Psychology, 86(1), 22-49.

Cohen, M. A., Gottlieb, M., Linn, J., \& Richardson, N. (2011). Deepwater drilling: Law, policy, and economics of firm organisation and safety. Vanderbilt Law Review, 64(6), 1853-1916.

Committee, T. R. (2014). The human factor: Process safety and culture. Technical Report, Society of Petroleum Engineers. 170575-TR.

Conchie, S. M. (2013). Transformational leadership, intrinsic motivation, and trust: A moderatedmediated model of workplace safety. Journal of Occupational Health Psychology, 18(2), 198210. https://doi.org/10.1037/a0031805

Conchie, S.M. \& Donald, I.J. (2009). The moderating role of safety-specific trust on the relation between safety-specific leadership and safety citizenship behaviours. Journal of Occupational Health Psychology, 14(2), 137-147.

Cooke, G., \& Sheers, R. (2003). Safety case implementation - An Australian regulator's experience. Institution of Chemical Engineers' Symposium Series, 149, 605-618.

Cullen, W. D. (1990). The public inquiry into the Piper Alpha disaster, London: Her Majesty's Stationery Office. 
Dahl, Ø., \& Olsen, E. (2013). Safety compliance on offshore platforms: A multi-sample survey on the role of perceived leadership involvement and work climate. Safety science, 54, 17-26. https://doi.org/10.1016/j.ssci.2012.11.003

Dalzell, G., (2011) Roles and Responsibility: Who carries the can-safety engineer or line manager? In Safety and Reliability. 31(1), 14-26. Taylor \& Francis. https://doi.org/10.1080/09617353.2011.11690927

Duddu, P. (2014). The world's worst offshore oil rig disasters. Offshore Technology. January.

Dunlap, E. S. (2011). Safety leadership. Professional Safety, 56(9), 42-49.

Eckle, P., \& Burgherr, P. (2013). Bayesian data analysis of severe fatal accident risk in the oil chain. Risk Analysis, 33(1), 146-160.

Elliot, T. S. (2001). Longford: The hazards of following fashions. In T. Kletz (Ed.), Learning from Accidents, 267-274. Gulf Professional Publishing.

European Commission (2015). The Seveso Directive - Prevention, preparedness and response. Retrieved June 5, 2018, from http://ec.europa.eu/environment/seveso/

Flin, R. \& Yule, S. (2004). Leadership for safety: Industrial experience. BMJ Quality \& Safety, 13(2), 45-51.

Hollnagel, E., Wears, R. L., Braithwaite, J. (2013). From Safety-I to Safety-II: A White Paper: European Organisation for the Safety of Air Navigation (EUROCONTROL).

Ivancevich, J., Konopaske, R., \& Matteson, M. (2007). Organisation Behaviour and Management. New York: McGraw-Hill Irwin.

Jenkins, T. (2013). Reflections on Kenneth E. Boulding's The Image: Glimpsing the Roots of Peace Education Pedagogy. Journal of Peace Education and Social justice, 7(1), 27-37.

Kelloway, E.K., Mullen, J. \& Francis, L. (2006). Divergent effects of transformational and passive leadership on employee safety. Journal of Occupational Health Psychology, 11(1), 76-86. https://doi.org/10.1037/1076-8998.11.1.76

Li, F., Jiang, L., Yao, X., \& Li, Y. (2013). Job demands, job resources and safety outcomes: The roles of emotional exhaustion and safety compliance. Accident Analysis \& Prevention, 51, 243251. https://doi.org/10.1016/j.aap.2012.11.029

Lu, C. S., \& Yang, C. S. (2010). Safety leadership and safety behaviour in container terminal operations. Safety Science, 48(2), 123-134.

Martínez-Córcoles, M., Gracia, F. J., Tomás, I., Peiró, J. M., \& Schöbel, M. (2013). Empowering team leadership and safety performance in nuclear power plants: A multilevel approach. Safety Science, 51(1), 293-301. https://doi.org/10.1016/j.ssci.2012.08.001

Martínez-Córcoles, M. \& Stephanou, K. (2017). Linking active transactional leadership and safety performance in military operations. Safety Science, 96, 93-101. https://doi.org/10.1016/j.ssci.2017.03.013

McBride, M., \& Collinson, G. (2011). Governance of process safety within a global energy company. Loss Prevention Bulletin, (217), 15-25.

Neal, A., Griffin, M.A. \& Hart, P.M. (2000). The impact of organisational climate on safety climate and individual behaviour. Safety Science, 34(1-3), 99-109. https://doi.org/10.1016/S09257535(00)00008-4

Northouse, P.G. (2018). Leadership: Theory and practice. Sage Publications.

Ojuola, J., Mostafa, S. and Mohamed, S., (2018, December 3-6). Construction Safety Leadership: A Complexity Perspective. The 1st International Conference on Construction Project Management and Construction Engineering (iCCPMCE-2018), Sydney, Australia, 104-109. 
Pat-El, I. E., Meijlink, L., \& Mol, P. (2014, November). Major Accidents and their impact-The EU Directive for Offshore Safety. In Abu Dhabi International Petroleum Exhibition and Conference. Society of Petroleum Engineers.

Pinheiro, A., Cranor, B. D., \& Anderson, D. O. (2011). Assessing risk: A simplified methodology for pre-job planning in oil \& gas production. Professional Safety, 56(09), 34-41.

Saleh, J. H., Haga, R. A., Favarò, F. M., \& Bakolas, E. (2014). Texas City refinery accident: Case study in breakdown of defense-in-depth and violation of the safety-diagnosability principle in design. Engineering Failure Analysis, 36,

121-133. https://doi.org/10.1016/j.engfailanal.2013.09.014

Schneider, J., Campbell, D., Vargo, C., \& Hall, R. (2011). An analysis of reported sustainabilityrelated efforts in the petroleum refining industry. The Journal of Corporate Citizenship, 44, 6984.

Stride, C. B., Turner, N., Hershcovis, M. S., Reich, T. C., Clegg, C. W., \& Murphy, P. (2013). Negative safety events as correlates of work-safety tension. Safety Science, 53, 45-50. https://doi.org/10.1016/j.ssci.2012.09.003

U.S. Energy Information Administration (2014). International Energy Outlook 2014: World Petroleum and Other Liquid Fuels. DOE/EIA-0484(2014). Retrieved June 5, 2018, from http://www.eia.gov/forecasts/ieo/pdf/0484\%282014\%29.pdf

Yin, R. K. (2003). Case Study Research: Design and Methods. Thousand Oaks, CA: (5), SAGE Publications. 